\title{
Applied surface analysis
}

\author{
Karl-Heinz Müller • Hubert Paulus • Mark Schülke
}

Published online: 13 July 2013

(C) Springer-Verlag Berlin Heidelberg 2013

The surface of a material is of great importance for its properties, fields of application or lifetime, since it is the surface with which every material interacts with its environment. Oxidation, corrosion and abrasion are examples of physical or chemical processes that can limit the use or the lifetime of products. On the other hand, today surfaces are treated in many ways in order to adapt their properties to special requirements, e.g. nanoscale structures in the electronics/semiconductor field, thin films for antireflection coatings, and the functionalization of surfaces in order to enhance certain chemical processes.

In connection with all of these tasks, surface analysis is crucial to obtain the required information about the surface, i.e. its elemental/chemical composition, its structure, its morphology, etc. Typical fields of application are:

1. The analysis of defects in or damage to products in order to find their causes.

2. The optimization of products, e.g. their surface reactivity or their resistivity against oxidation or abrasion.

3. Controlling manufacturing processes, e.g. in semiconductor structuring.

Today there are many specialized methods and tools for surface analysis. One of the most popular tools is X-ray

Published in the topical collection Applied Surface Analysis with guest editors Karl-Heinz Müller, Hubert Paulus, and Mark Schülke.

K.-H. Müller $\cdot$ H. Paulus

Institut für Technologie- und Wissenstransfer im Kreis Soest e.V, University of Applied Sciences of South Westphalia,

Lübecker Ring 2, 59494 Soest, Germany

M. Schülke $(\bowtie)$

University of Applied Sciences of South Westphalia,

Lübecker Ring 2, 59494 Soest, Germany

e-mail: schuelke.mark@fh-swf.de photoelectron spectroscopy (XPS; also called electron spectroscopy for chemical analysis), which provides quantitative information not only about the composition of a surface but also about the chemical bonding states of the elements. Auger electron spectroscopy offers similar information but with much better lateral resolution than XPS (below $100 \mathrm{~nm}$ today). Mass-spectrometric methods such as secondary ion mass spectrometry (SIMS), on the other hand, are extremely sensitive regarding element concentration and allow the detection of elements (including $\mathrm{H}$ and $\mathrm{He}$, contrary to XPS, for example), whole molecules and molecular fragments up to 1,000 amu (quadrupole mass spectrometer) or even 10,000 amu with time-of-flight SIMS; with SIMS, depth profiles, thin films and segregation effects can be examined too. Scanning electron microscopes allow topographic investigations with extremely high lateral resolution (although less surface sensitive than, e.g., Auger electron spectroscopy), often combined with element identification using energy-dispersive $\mathrm{X}$-ray spectroscopy. These are only three examples of many, not to mention optical methods or structural analysis.

The articles in this topical collection on applied surface analysis present several sophisticated applications of these and other methods, e.g. the use of energy-dispersive X-ray spectroscopy and electron spectroscopy methods for examining the surface conditions of high-strength steels after hotdip galvanizing, the combination of time-of-flight SIMS and microscopic methods for the generation of images with topographic and mass-spectrometric information, and new preparation methods prior to the XPS analysis of organic coatings.

These and other subjects of applied surface analysis were presented at the 17th Conference on Applied Surface Analysis (AOFA 17) in Soest, Germany. This conference is held every 2 years and will take place again in Kaiserslautern, Germany, in 2014. 
We sincerely hope that you enjoy reading the articles in this special. We thank all authors for their very interesting contributions and the editorial office and the editors for their cooperation and friendly support.

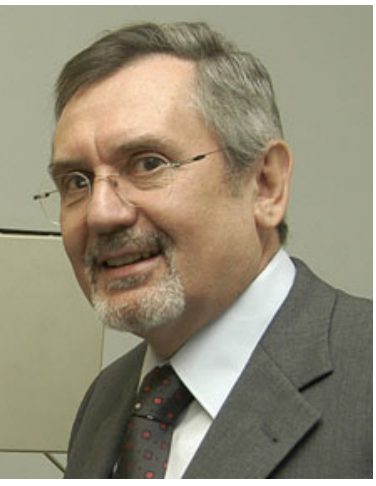

Karl-Heinz Müller is Professor at the University of Applied Sciences of South Westphalia in Soest, and executive director and scientific head of the Institut für Technologieund Wissenstransfer TWS. His scientific interests are instrumental surface analysis, the storage of hydrogen in metals and renewable energies.

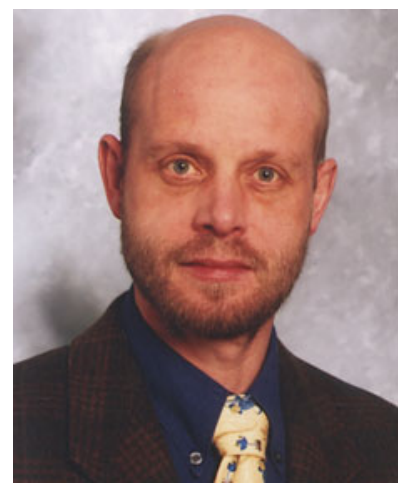

Hubert Paulus is Head of the Surface Analysis Laboratory of the Institut für Technologie- und Wissenstransfer TWS. His scientific interests are surface analysis (especially mass spectrometry) and the storage of hydrogen in metals.

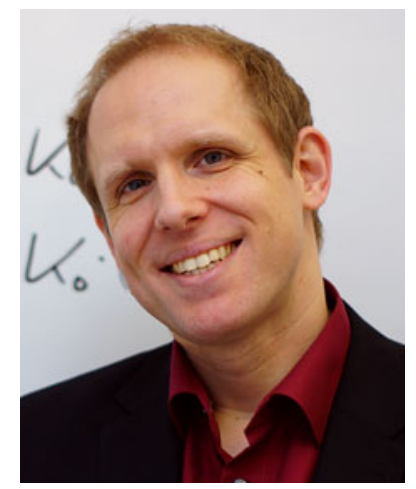

Mark Schülke is a research associate at the University of Applied Sciences of South Westphalia in Soest. His research work is focused on surface analysis and storage of renewable energies (especially in metal hydrides). 